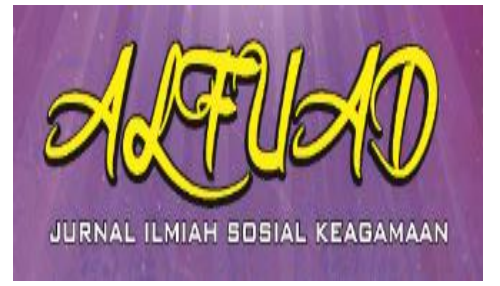

ALFUAD JOURNAL, 2 (2), 2018, (37-47)

(Print ISSN 2614-4786)

Available Online at

http://ecampus.iainbatusangkar.ac.id/ojs/index.php/alfuad

\title{
PEMBERDAYAAN MASYARAKAT MELALUI PROGRAM POS KEADILAN PEDULI UMMAT (PKPU) DI PASAR LALANG KELURAHAN KURANJI KOTA PADANG
}

\author{
Beni Putra Hanafi \\ Institut Agama Islam Negeri Batusangkar \\ Indonesia \\ E-mail: beniputra_hanafi@yahoo.co.id
}

\begin{abstract}
The definition of poverty is very diverse, ranging from just the inability to fulfill basic needs and improve conditions to a broader understanding that includes social and moral components. The purpose of this study was to analyze the process of Community Empowerment through the PKPU Program in Pasar Lalang, Kuranji Village, Padang City. The usefulness of this research is to reveal the process of community empowerment through the PKPU program at Pasar Lalang, to find out how far the empowerment process carried out by PKPU Kota Padang in empowering the Lalang Market community in accordance with the concepts of empowerment. This research is in the form of qualitative descriptive, namely presenting facts and symptoms in the field and then analyzed so that the final conclusions are clearly understood. In collecting data the author uses the method of interview, observation and documentation. Based on the results of the study obtained several facts seen from various things. First seen from the process of liberation and awareness carried out by PKPU, the realization was in the form of socialization and enlightenment in the form of lectures held at mosques and open fields that had been prepared in advance. Pasar Lalang community is given the motivation to be able to change their lives for the better. After that PKPU socialized the programs they will provide to the community.
\end{abstract}

Keywords: PKPU, Community Empowerment

\section{PENDAHULUAN}

Dalam rangka meningkatkan ekonomi bangsa, konsep-konsep pembangunan yang ditawarkan oleh negara-negara maju dan sudah dilaksanakan di negaranegara berkembang justru tidak menyelesaikan masalah, tetapi semakin menimbulkan kesengsaraan dan kemiskinan diberbagai negara, termasuk Indonesia. Kenyataan yang menandai perkembangan kota-kota besar di negara sedang berkembang adalah mereka cenderung berkembang secara luar biasa, namun ironinya pertumbuhan kota yang ekspansif itu ternyata tidak diimbangi dengan tingkat pertumbuhan ekonomi yang cukup tinggi guna memberikan kesempatan kerja bagi penduduk yang bertambah cepat di kota itu.

Di satu sisi mungkin benar bahwa kota berkembang menjadi metropolis tampak 
makin semarak, dipenuhi dengan pembangunan sarana fisik seperti membangun gedung, jalan, jembatan, pelabuhan, atau pembangunan lainnya relatif mudah dan kongkrit. Artinya pembangunan pembangunan fisik mudah dilihat dan dirasakan manfaatnya. Berbeda dengan non fisik, misalnya pembangunan mental, pendidikan, atau pelatihan memang tidak Nampak dan tidak mudah dirasakan hasilnya.

Proses pendidikan misalnya, dari usia bayi dan anak-anak, baru dirasakan setelah dewasa yaitu menjadi orang yang cerdas, memiliki berbagai kecakapan dan akhlak mulia, serta mampu menciptakan berbagai hal yang dapat bermanfaat bagi ummat manusia dan makhluk hidup lainnya.

Al-Qur'an telah menjelaskan bahwa takutlah kepada Allah SWT, bagi orangorang yang melupakan orang lain yang membutuhkan bantuannya dan hidup lemah di antaranya. Hal ini juga dipertegas lagi oleh hadis Rasulullah SAW. Yaitu sebagai berikut:

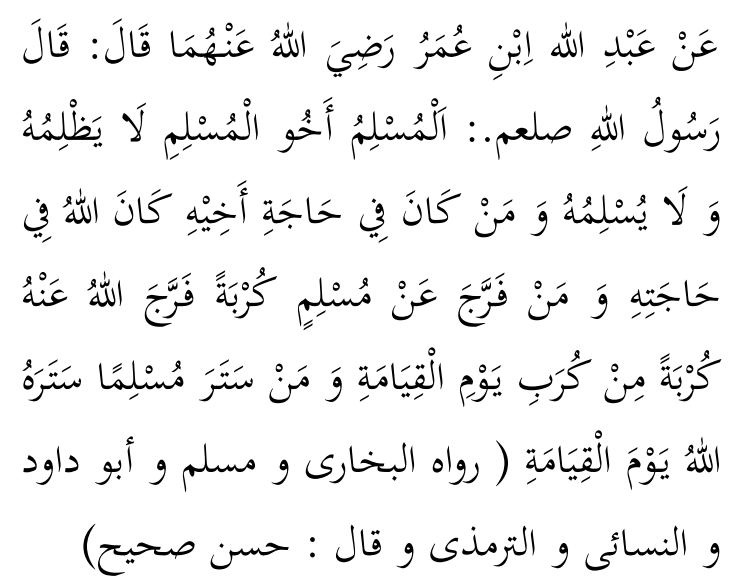

Artinya:
"Abdullah ibn Umar r.a berkata bahwa Rasulullah SAW bersabda,"seorang Muslim adalah saudaranya Muslim (yang lain). Dia tidak menganiaya dan menyerahkan saudaranya. Barang siapa yang memenuhi kebutuhan saudaranya, Allah memenuhi kebutuhanNya. Barang siapa melepaskan dari seorang muslim satu kesusahan dari kesusahan-kesusahan dunia Niscaya Allah melepaskan dia dari kesusahan-kesusahan hari kiamat. Dan barangsiapa yang menutup aib seorang muslim niscaya Allah menutupi aibnya di dunia dan akhirat. Dan Allah selamanya menolong hamba-Nya, selama hamba-Nya menolong saudaranya.(Diriwayatkan oleh Al-Bukhari, Muslim, Abu Daud, An-Nasa'i dan Tarmidzi.

Pasar Lalang merupakan salah satu daerah pinggiran yang berada di Kelurahan Kuranji, Kecamatan Kuranji Kota Padang. Pasar Lalang merupakan daerah yang jauh dari kebisingan kota. Daerah ini merupakan daerah yang dikelilingi oleh bukit-bukit, memiliki lahan pertanian yang cukup luas dan hutan yang masih terjaga serta dialiri oleh sungai. Dari hasil pengamatan yang penulis lakukan di Pasar Lalang Kel. Kuranji Kota Padang, penulis melihat bahwa begitu banyak bantuan yang datang ke daerah ini, misalnya berupa pemberian dana tanpa meminta pertanggung jawaban dari bantuan itu sehingga masyarakat tersebut bergegas atau berbondong-bondong untuk memperolehnya.

Pasar Lalang merupakan daerah atau bagian dari Kelurahan Kuranji Kota Padang yang memiliki penduduk sebanyak 1257 orang yang tergabung kedalam 314 kepala keluarga. Yang bekerja sebagai PNS 
sebanyak 10\%, Tani 30\%, Buruh 15\%, Swasta 15\%, dan Buruh Tani 30\%. Dengan kondisi wilayah $45 \%$ areal pertanian, $25 \%$ pemukiman penduduk, 30\% perkebunan, serta daerah ini juga di aliri sungai Pasar Lalang.

\section{Lembaga Kemanusiaan Nasional \\ PKPU Padang hadir dalam rangka} menjalankan beberapa programnya di daerah Pasar Lalang ini dengan tujuan untuk meningkatkan kesejahteraan masyarakatnya. Bantuan tersebut tidak hanya diberikan begitu saja kepada masyarakat, bantuan ini nantinya juga harus dipertanggungjawabkan oleh masyarakat penerima bantuan dengan tujuan agar masyarakat bisa mandiri dan mampu meningkatkan taraf kehidupannya.

Pemberdayaan masyarakat adalah proses perubahan yang dilakukan secara sistematis dengan tujuan menjadikan masyarakat mandiri dalam memenuhi kebutuhan dan mampu mengaktualisasikan diri. Maksud dari mampu di sini yaitu mempunyai kekuatan dan kekuasaan dalam mengatur kehidupan dari segala aspek. Pemberdayaan Masyarakat juga berarti sebagai upaya untuk membangun daya masyarakat dengan mendorong, memotivasi, dan membangkitkan kesadaran akan potensi yang dimiliki serta berupaya untuk mengembangkannya.

Masyarakat merupakan sekumpulan individu yang mendiami suatu wilayah. Masyarakat mencakup beberapa unsur yaitu: (a) Masyarakat merupakan manusia yang hidup bersama. (b) Bercampur dalam waktu yang cukup lama. (c) Mereka sadar bahwa mereka merupakan suatu kesatuan. (d) Mereka merupakan suatu sistem hidup bersama.

Masyarakat yang dimaksud dalam penelitian ini yaitu masyarakat yang berada di daerah Pasar Lalang Kel. Kuranji Kota Padang. (1) Lembaga PKPU adalah Lembaga Kemanusiaan Nasional Pos Keadilan Peduli Ummat. Lembaga ini mempunyai tujuan membangun masyarakat yang mandiri dan inovatif. (2) Pasar Lalang adalah sebuah daerah pinggiran yang berada di Kelurahan Kuranji Kecamatan Kuranji Kota Padang yang memiliki penduduk sebanyak 1257 orang yang tergabung kepada 314 kepala keluarga

\section{Kajian Kepustakaan}

Berdasarkan penelusuran yang penulis lakukan ternyata penelitian yang berjudul pemberdayaan masyarakat Desa Binaan Pasar Lalang melalui program PKPU belum ada yang meneliti. Akan tetapi penelitian yang terkait dengan pokok pembahasan mengenai program PKPU sudah ada. Hanya saja penekanan-penekanan penelitian yang telah dilakukan tersebut berbeda dengan penekanan yang dilakukan dalam penelitian ini. Diantara penelitian yang telah dilakukan sebagai berikut: 
Beni Putra Hanafi: Pemberdayaan Masyarakat Melalui Program Pos Keadilan Peduli Ummat ...

Penelitian yang dilakukan oleh Novita Sari mahasiswi Manajemen Dakwah 2010, mengenai "Manajemen Pos Keadilan Peduli Ummat (PKPU) dalam pengelolaan zakat online". Pada penelitian tersebut, peneliti mendapatkan hasil bahwa pengelolaan zakat online dapat memudahkan para muzakki dalam membayar zakat, serta adanya bentuk-bentuk zakat online yang dilakukan PKPU seperti zakat Via ATM banking, Zakat Internet, Zakat SMS, dan Zakat melalui kantor Pos.

Dilihat dari beberapa penelitian di atas, terletak adanya perbedaan dengan penelitian yang akan penulis lakukan. Penelitian kali ini penulis akan memaparkan bagaimana Proses Pemberdayaan Masyarakat Pasar Lalang melalui program PKPU.

\section{Adapun}

program-program

pemberdayaan masyarakat yang direalisasikan oleh lembaga PKPU tersebut antara lain: Program Komunitas Sehat, Beasiswa Peduli Generasi, Sebar Qurban Nusantara, dan Program Sinergitas Pemberdayaan Ekonomi Komunitas.

\section{Konsep-konsep Pemberdayaan}

\section{Masyarakat}

\section{Definisi Pemberdayaan}

Secara konseptual, pember-dayaan atau pemerkuasaan (empower-ment) berasal dari kata power (kekuasaan atau keberdayaan) Karenanya ide utama pemberdayaan bersentuhan dengan kemampuan untuk membuat orang lain melakukan apa yang diinginkan, terlepas dari keinginan dan minat mereka.

Istilah pemberdayaan masya-rakat mengacu pada kata "empowerment" yang berarti penguatan, yaitu sebagai upaya untuk mengaktualisasikan potensi yang sudah dimiliki oleh masyarakat. Jadi pendekatan pemberdayaan masyarakat titik beratnya adalah penekanan pada pentingnya masyarakat lokal yang mandiri sebagai suatu sistem yang mengorganisir diri mereka. Pendekatan pemberdayaan masyarakat yang diharapkan adalah yang dapat memposisikan individu sebagai subjek bukan sebagai objek.

\section{Proses Pemberdayaan Masyarakat}

Pemberdayaan sebagai suatu proses merupakan sesuatu yang berkesinambungan dimana komunitas atau kelompok masih ingin melakukan perubahan serta perbaikan dan tidak hanya terpaku pada satu program saja. Pemberdayaan adalah sebuah "proses menjadi", bukan sebuah "proses instan". Sebagai proses, pemberdayaan mempunyai tiga tahapan yaitu, penyadaran, pengkapasitasan, dan pendayaan.

\section{Tiga Tahapan Pemberdayaan}

\section{Prinsip-prinsip Pemberdayaan}

Dalam memberdayakan suatu masyarakat, konsep pemberdayaan yang digunakan tentu berbeda-beda, melihat keadaan masyarakat yang diberdayakan. 
Dalam pengertian konvensional, konsep pemberdayaan sebagai terjemahan empowerment mengandung dua pengertian, yaitu: Empowerment yang pertama: to give power or authority to atau memberi kekuasaan, mengalihkan kekuatan, atau mendelegasikan otoritas ke pihak lain. Adapun arti yang kedua: to give ability to atau to enable atau usaha untuk memberi kemampuan atau keberdayaan. Eksplisit dalam pengertian ke dua ini adalah bagaimana menciptakan peluang mengaktualisasikan keberdayaan seseorang.

\section{Tingkatan Pemberdayaan}

Sudah saatnya paradigma pembangunan yang selalu menempatkan pemerintah sebagai sumber segala-galanya digeser dengan menempatkan masyarakat sebagai pemain utama. Kekuasaan sejatinya dikembalikan kepada masyarakat agar masyarakat menjadi aktor utama dalam pembangunan. Sebuah proses seharusnya dilakukan untuk meningkatkan derajat keberdayaan masyarakat sampai kepada tingkat keberdayaan masyarakat yang optimal.

\section{Konsep tentang Masyarakat}

\section{Pengertian Masyarakat}

Menurut Koentjaraningrat

masyarakat adalah sekumpulan manusia yang saling "bergaul" atau dengan istilah ilmiah yaitu saling "ber-interaksi". Suatu kesatuan manusia dapat mempunyai prasarana agar warganya dapat saling berinteraksi (Koentjaraningrat, 2013)

Manusia adalah makhluk sosial yang hidup bermasyarakat, hidup bermasyarakat dapat diartikan sebagai hidup dalam suatu pergaulan. Kata masyarakat berasal dari bahasa arab 'syaraka' yang artinya ikut serta (partisipasi). Sedangkan dalam bahasa inggris dipakai istilah 'society' yang berasal dari kata 'socius' yang artinya kawan.

\section{Unsur-unsur Masyarakat}

Adanya bermacam-macam wujud kesatuan kelompok manusia menyebabkan bahwa manusia memerlukan beberapa istilah untuk membeda-bedakan berbagai macam kesatuan manusia itu sendiri. Kecuali istilah yang paling lazim yaitu masyarakat, ada istilah lain untuk menyebut kesatuankesatuan khusus yang merupakan unsurunsur dari masyarakat yaitu sebagai berikut: (1) Masyarakat. Istilah yang paling lazim dipakai untuk menyebut kesatuan-kesatuan hidup manusia, baik dalam tulisan ilmiah maupun dalam bahasa sehari-hari adalah masyarakat. Seperti yang telah dijelaskan di atas bahwa masyarakat merupakan sekumpulan manusia yang saling bergaul atau bisa juga disebut dengan saling berinteraksi.

Kategori sosial (3) Masyarakat sebagai suatu kelompok manusia yang sangat umum sifatnya mengandung kesatuan-kesatuan yang sifatnya lebih khusus tetapi belum tentu mempunyai syarat pengikat yang sama 
dengan suatu masyarakat. Kategori sosial adalah kesatuan manusia yang terwujud karena adnya suatu cirri atau suatu kompleks cirri-ciri objektif yang dapat dikenakan kepada manusia-manusia itu. (4) Golongan sosial.

Suatu golongan sosial juga merupakan satu kesatuan manusia yang ditandai oleh suatu ciri tertentu. Bahkan sering kali ciri itu juga dikenakan kepada mereka oleh pihak luar kalangan mereka sendiri. Walaupun demikian suatu kesatuan manusia yang disebut golongan sosial itu mempunyai ikatan identitas sosial. (1) Kelompok dan perkumpulan. Suatu kelompok atau group juga merupakan suatu masyarakat karena memenuhi syaratsyaratnya, dengan adanya sistem interaksi antara para anggota, dengan adanya adatistiadat serta sistem norma yang mengatur interaksi itu, dengan adanya kontinuitas serta dengan adanya rasa identitas yang mempersatukan semua anggota tadi.

\section{PEMBAHASAN}

\section{Profil Lembaga Kemanusiaa Nasional}

\section{PKPU dan Daerah Pasar Lalang}

Lembaga Kemanusiaan Nasional PKPU merupakan sebuah lembaga yang bergerak di bidang kemanusiaan dan sebagai badan amil zakat. Lembaga Kemanusiaan
Nasional PKPU menyadari bahwa potensi dana ummat yang berasal dari zakat, infaq dan shadaqah sangat besar. Sebagai negara yang berpenduduk mayotitas muslim,

Tabel I

Organisasi Sosial Masyarakat

Sumber: Data Kantor Lurah Kelurahan

Kuranji 2015

\begin{tabular}{|c|c|c|}
\hline No & Nama Organisasi & Jumlah \\
\hline 1 & Jumlah Majlis Taklim & 2 \\
\hline 2 & Jumlah TPA & 1 \\
\hline 3 & Jumlah PHBI & 1 \\
\hline 4 & Jumlah Pengurus kurban & 2 \\
\hline 5 & $\begin{array}{l}\text { Jumlah Pengurna anak } \\
\text { yatim }\end{array}$ & 3 \\
\hline 6 & Jumlah lembaga adat & 2 \\
\hline 7 & Jumlah Pengurus zaksat & 3 \\
\hline 8 & $\begin{array}{l}\text { Jumlah Pengurus } \\
\text { Kematian }\end{array}$ & 1 \\
\hline 9 & $\begin{array}{l}\text { Jumlah Penguras Kuburan } \\
\text { umum }\end{array}$ & 4 \\
\hline 10 & Jumlah Pengurus Masjid & 4 \\
\hline 11 & $\begin{array}{l}\text { Jumlah Pengurgas } \\
\text { musholla }\end{array}$ & 9 \\
\hline 12 & $\begin{array}{l}\text { Jumlah Pengurus Remaja } \\
\text { Masjid }\end{array}$ & 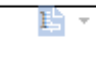 \\
\hline
\end{tabular}

Indonesia bisa mengop-timalkan dana zakat, infak dan sadaqah (ZIS)-nya untuk memberdayakan masyarakat.

Tabel II

Jumlah Penduduk Berdasarkan

\begin{tabular}{|c|l|c|}
\hline No & Jenis Kelamin & Jumlah (Jiwa) \\
\hline 1 & Laki-Laki & 633 \\
\hline 2 & Perempuan & 624 \\
\hline Jumlah & $\mathbf{1 . 2 5 7}$ \\
\hline
\end{tabular}

Jenis Kelamin

Sumber: Data Kantor Lurah Kelurahan Kuranji 2015 
Tabel III

Data Keluarga Miskin

\begin{tabular}{|l|l|l|}
\hline 1 & Penerima Jamkesda & $\begin{array}{l}986 \\
\text { iiwa }\end{array}$ \\
\hline 2 & Penerima Jamkesmas & 101 jiwa \\
\hline 3 & Penerima BPJS & 212 jiwa \\
\hline 4 & $\begin{array}{l}\text { Penerima Manfaat } \\
\text { Raskin }\end{array}$ & $\mathrm{kk}$ \\
\hline 5 & Penerima Kartu KPS & $248 \mathrm{kk}$ \\
\hline 6 & Anak yatim & 27 jiwa \\
\hline
\end{tabular}

I

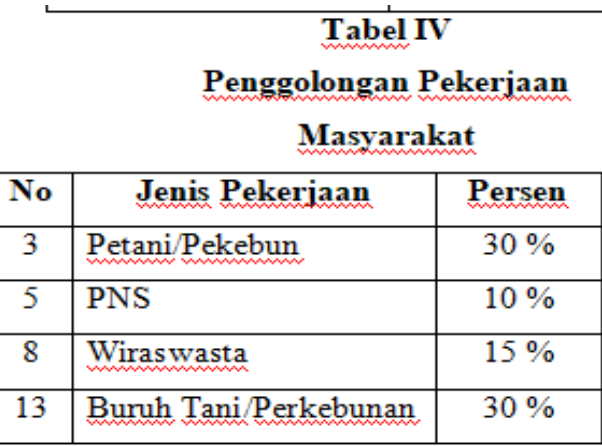

Berdasarkan tabel di atas diketahui jumlah penduduk daerah Pasar Lalang Kelurahan Kuranji Kota Padang. Masyarakat Pasar lalang berjumlah 1.257 jiwa terdiri dari laki-laki sebanyak 633 orang jiwa dan perempuan sebanyak 624 jiwa. Jumlah Kepala Keluaraga sebanyak 314 KK.

Daerah Pasar Lalang merupakan daerah pertanian maka sebagian besar penduduknya bermata pencaharian sebagai petani.

\section{Program Lembaga Kemanusiaan}

\section{Nasional PKPU Padang di Pasar Lalang}

Lembaga Kemanusiaan Nasional

PKPU Padang memiliki berbagai macam program yang dilaksanakan diberbagai tempat. Baik memberikan bantuan kebencanaan, bantuan santunan, pemberian hewan qurban, beasiswa, dan lainnya. Lembaga Kemanusiaan Nasional PKPU Padang memiliki tujuh program unggulan yang dilaksanakan diberbagai tempat termasuk di daerah binaan Lembaga Kemanusiaan Nasional PKPU Padang. Dari tujuh program unggulan tersebut, ada empat program yang di laksanakan di Pasar Lalang Kel. Kuranji Kota Padang.

\section{Proses Pemberdayaan Masyarakat melalui Program PKPU}

Dari hasil observasi yang penulis lakukan di Pasar Lalang dua minggu setelah proses penyadaran yang diberikan oleh PKPU kepada masyarakat, penulis melihat dampak bagi masyarakat setelah pencerahan diberikan ternyata masyarakat masih seperti biasanya, belum ada terlihat perubahan kearah yang lebih baik, buktinya salah seorang warga yang bernama Husaini. Pak Husaini kegiatan kesehariannya adalah buruh bangunan yang tidak menetap, meskipun sudah diberikan penyadaran oleh PKPU namun pak Husaini masih bekerja sebagai buruh bangunan yang tidak menetap padahal dia punya lahan seperti sawah dan lading yang harus digarab.

\section{Proses Mengidentifikasi Masalah}

Suatu pekerjaan yang tidak mudah dilakukan dalam setiap pemberdayaan 
masyarakat adalah mengidentifikasi masalah masyarakat. Seringkali pelaku pemberdayaan salah langkah dalam menentukan kebutuhan masyarakat karena tidak bisa membedakan antara kebutuhan yang sesungguhnya dengan kebutuhan yang dirasakan, atau dengan kata lain antara kebutuhan dengan keinginan masyarakat.

Terkait dengan hal di atas, penulis mewawancarai Ramdan, untuk memperkuat argument penulis dalam mengetahui proses mengidentifikasi masalah masyarakat, berikut uraiannya:

"Sebelum memberikan bantuan, kami mendatangi RT/RW setempat untuk menanyakan perihal masyarakat setempat. Kami juga menanyakan tentang bantuan apa yang patut diberikan kepada masyarakat serta siapa-siapa saja masyarakat yang berhak menerimanya. Hal ini kami tanyakan kepada Rt/Rw karena menurut kami merekalah yang mengerti dengan keadaan masyarakatnya."

Pernyataan di atas juga diperkuat oleh penjelasan yang penulis pertanyakan kepada Pak Safrinal, dengan penjelasan berikut ini: "Bantuan yang akan diberikan oleh pihak PKPU kepada masyarakat Pasar Lalang ini, terlebih dahulu melalui musyawarah bersama kami. Pihak PKPU mendiskusikan tentang bantuan-bantuan yang akan diberikannya dan kami menyampaikan bantuan apa yang cocok untuk diberikan kepada masyarakat Pasar Lalang. Data yang kami berikan berdasarkan pengamatan kami terhadap masyarakat miskin yang memerlukan bantuan".

\section{Proses Menggerakkan Partisipasi dan}

\section{Etos Swadaya Masyarakat}

Pemberdayaan pada hakikatnya adalah untuk menyiapkan masyarakat agar mereka mampu dan mau secara aktif berpartisipasi dalam setiap program dan kegiatan pembangunan yang bertujuan untuk memperbaiki mutu hidup (kesejahteraan) masyarakat, baik dalam pengertian ekonomi, sosial, fisik, maupun mental.

Masyarakat dengan serius melakukan hal-hal yang diperintahkan untuk dilakukan sebagaimana mestinya. Sebagai contoh, penulis menemukan masyarakat yang sangat bersemangat ketika diberikan bantuan ternak itik. Semangat mereka terlihat dari cara mereka dalam melaksanakan perintah dari pemberi program sewaktu diberikan pendampingan serta pelatihan dalam pemeliharaan ternak itik yang baik.

Pengamatan penulis di atas diperkuat oleh wawancara yang telah penulis lakukan bersama Pak Shaleh, mengenai tanggapannya terhadap program ternak itik yang diberikan oleh pihak PKPU:

"Beternak itik merupakan suatu hal yang baru bagi saya, karena sebelumnya saya tidak pernah beternak itik. Namun saya sangat senang menerima bantuan ini, 
apalagi saya sangat mengharapkan adanya tambahan dari penghasilan keluarga kami”.

Respon Pak Shaleh tersebut menggambarkan bahwa program yang diberikan oleh pihak PKPU sangat diharapkan oleh masyarakat Pasar Lalang. Masyarakat sangat mengharapkan dengan bantuan tersebut dapat membantu perekonomian keluarga mereka. Dengan begitu, masyarakat bersemangat melaksanakan kegiatan pendampingan ternak itik. Hal ini diperjelas pula oleh Heldi Yusra dengan hasil wawancara yang penulis lakukan, sebagai berikut: "Masyarakat sangat bersemangat menjalankan hal-hal yang kami anjurkan dalam proses pendampingan untuk ternak itik. Walaupun banyak di antara mereka yang belum mempunyai pengalaman sebelumnya, tapi mereka aktif bertanya hal-hal yang harus mereka lakukan serta bertanya hal yang tidak mereka ketahui”.

\section{KESIMPULAN DAN SARAN}

Proses pemberdayaan yang penulis ungkap pada penelitian ini terkait kepada tiga proses pemberdayaan yaitu: (1) Proses pembebasan dan penyadaran. Dalam hal ini dapat penulis ungkapkan bahwa proses pembebasan dan penyadaran yang dilakukan oleh pihak Lembaga Kemanusiaan PKPU dalam memberdayakan masyarakat Pasar Lalang, belum efektif dalam pelaksanaannya berdasarkan konsep-konsep pemberdayaan yang penulis jadikan acuan. (2) Proses menggerakkan partisipasi dan etos swadaya masyarakat. Dalam hal ini terlihat bahwa pihak PKPU berusaha mengajak masyarakat untuk mengikuti dengan baik program yang diberikan. Masyarakat bersedia melakukan hal-hall yang dianjurkan selama pendampingan dilakukan. Sikap peduli masyarakat terhadap program diberikan oleh pihak PKPU sangat membantu untuk memperlancar berjalannya program.

Dari pemaparan yang telah penulis tuangkan dalam penelitian ini, penulis bermaksud ingin memberikan suatu saran kepada pihak PKPU sebagai lembaga yang bernaung dalam memberdayakan masyarakat. Saran yang penulis berikan hendaknya pihak PKPU dalam memberdayakan masyarakat menggunakan konsep-konsep pemberdayaan sebagaimana mestinya, agar mencapai hasil yang diinginkan oleh semua pihak.

\section{DAFTAR PUSTAKA}

Huraerah, A. (2001). Pengorganisasian dan Pengembangan Masyarakat; Model dan Strategi Pembangunan Berbasis Kerakyatan. Bandung: Humaniora.

Alfitri. (2011). Community Development; Teori dan Aplikasi. Yogyakarta: Pustaka Pelajar.

Taguh, A. (2004). Kemitraan Dan ModelModel Pemberdayaan. Yogyakarta: Gava Media.

Muslim, A. (2009). $\begin{aligned} & \text { Metodologi } \\ & \text { Pengembangan } \\ & \text { Yogyakarta: TERAS. }\end{aligned}$


Walgito, B. (2003). Psikologi Sosial Suatu Pengantar. Yogyakarta: Adi Yogyakarta.

Departemen Agama RI. (1989). “Al-Qur'an dan Terjemahnya." Semarang: CV. Toha Putra.

Departemen Pendidikan Nasional. (2005). Kamus Besar Bahasa Indonesia. Jakarta: Balai Pustaka.

Dokumen RW 007 Pasar Lalang.

Dokumen Badan Pemberdayaan Masyarakat (BPM) Provinsi Sumatera Barat

Dokumentasi, Profil Lembaga Kemanusiaan PKPU 2011

Suharto, E. (2005). Membangun Masyarakat Memberdayakan Rakyat: Kajian Strategis Pembangunan Kesejahteraan Sosial dan Pekerjaan Sosial. Bandung: PT Refika Aditama.

Shadily, H. (1984). Sosiologi Untuk Masyarakat Indonesia. Jakarta: Bina Aksara.

Usman, H., \& Akbar, P. S. (1996) Metodologi Penelitian Sosial. Jakarta: Bumi Aksara.

Thamrin, H., et al. (2009) Kemiskinan di Riau Realitas dan Kebijakan, Pekanbaru: Suska Press.

Imansyah. (2016) Pemberdayaan Masyarakat Dalam Pengelolaan Lingkungan

Soehartono. (2008). Metode Penelitian Sosial. Bandung: PT Remaja Rosdakarya.

Adi, I. R. (2002). Pemikiran-Pemikiran Dalam Kesejahteraan Sosial, Jakarta: Penerbitan fakultas ekonomi UI Seri II.

Salam, J. (2011). Pendayagunaan Dana Zis Pada Pos Keadilan Peduli Ummat Dalam Upaya Meningkatkan Gizi Masyarakat Bintaro-Tanggerang Selatan Melalui Program Ibu Sadar Gizi (BUDARZI), skripsi Fakultas Ilmu dakwah dan Ilmu komunikasi Jurusan Manajemen Dakwah. tidak diterbitkan.

Khoriddin. (1992). Pembangunan Masyarakat, Yogyakarta: Liberty.

Koentjaraningrat. (1991). Metode Penelitian Masyarakat. Jakarta: Media.
Saputra, L. S. (2007). Pendidikan Kewarganegaraan, Bandung: Setia Purna Inves.

Bungin, M. B. (2003). Analisa Data Penelitian Kualitatif Pemahaman Filosofis dan Metodologis Kerah Penguasaan Model Aplikasi. Jakarta: PT. Raja Grafindo Persada.

Zuhdi, M. (1994). Masail Fiqhiyah, Jakarta: $\mathrm{CV}$. Haji Masagung.

Machendrawaty, N. et al, (2001) Pengembangan Masyarakat Islam dari Ideologi, Strategi, sampai Tradisi, Bandung: PT. Remaja Rosdakarya.

Achmadi, N. (2005). Metodologi Penelitian. Jakarta: Bumi Aksara.

Zuriah, N. (2005). Metodologi Penelitian Sosial dan Pendidikan. Jakarta: Bumi Aksara.

Ratna, N. K. (2010). Metodologi Penelitian Kajian Ilmu Sosial Humaniora pada Umumnya. Yogyakarta: Pustaka Pelajar

Anwas, O. M. (2013). Pemberdayaan Masyarakat Di Era Global. Bandung: Alfabeta.

Syafe'I, R. (2000). "Al-Hadis (Aqidah, Akhlaq, Sosial, dan Hukum)", Bandung: Pustaka setia.

Wrihatnolo, R. R. (2007). Manajemen Pemberdayaan: Sebuah Pengantar dan Panduan untuk Pemberdayaan Masyarakat. Jakarta: PT Elex Komputindo.

Riduwan. (2005). Dasar-Dasar Statistik, Bandung: Alfabeta.

Santoso, S. (1986). Komunikasi, Persuasi, Dan Disiplin Dalam Pembangunan Nasional. Bandung: Alumni.

Setiana, L. (2007). Teknik Penyuluhan Dan Pemberdayaan Masyarakat, dalam Nurjanah, ed, Implikasi Filsafat Konstruktivisme Untuk Pemberdayaan Masyarakat. Yogyakarta: UIN Sunan Kalijaga Press, Cet-1.

Soekanto, S. (1993). Kamus Sosiologi. Jakarta: Raja Grafindo Persada.

Soekanto, S. (2007). Sosiologi Suatu Pengantar. Jakarta: PT. Raja Grafindo Persada. 
Wingnyosoebroto, S. (2005). Dakwah Pemberdayaan Masyarakat Paradigma Aksi Metodologi. Yogyakarta: Pustaka Pesantren.

Notoatmodjo, S. (1997). Ilmu Kesehatan Masyarakat. Jakarta: PT. Rineka Cipta.

Sugiyono. (2010). Metode Penelitian Kuantitatif Kualitatif dan $R \& D$, Bandung: Alfabeta.
Arikunto, S. (2002). Prosedur Penelitian Suatu Pendekatan Praktis, Jakarta: Renika Cipta.

Usman, S. (2015). Esai-Esai Sosiologi Perubahan Sosial. Yogyakarta: Pustaka Pelajar.

Mardikanto, T., \& Soebiato, P. (2003). Pemberdayaan Masyarakat dalam Persfektif Kebijakan Publik. Bandung: Alfabeta. 